\title{
Role of L-carnitine in female infertility
}

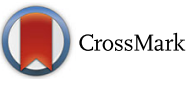

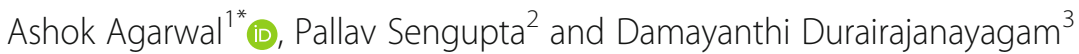

\begin{abstract}
Background: L-carnitine (LC), and its acetylated form, acetyl L-carnitine (ALC), have immense functional capabilities to regulate the oxidative and metabolic status of the female reproductive system. The vulnerability of this system to free radicals demand for advanced strategies to combat them. For this purpose, the 'quasi vitamins' LC and ALC can be used either individually, or in combination with each other or with other antioxidants.

Main body: This review (a) summarizes the effects of carnitines on female fertility along with the findings from various in vivo and in vitro studies involving human, animal and assisted reproductive technology, and (b) proposes their mechanism of actions in improving female fertility through their integrated actions on reducing cellular stress, maintaining hormonal balance and enhancing energy production. They reportedly aid $\beta$-oxidation in oocytes, maintain its cell membrane stability by acetylation of phospholipids and amphiphilic actions, prevent free radicalinduced DNA damage and also stabilize acetyl Co-A/Co-A ratio for adequate acetyl storage as energy supply to maintain the robustness of reproductive cells.

Conclusion: While both LC and ALC have their applications in improving female fertility, ALC is preferred for its better antioxidant properties and LC for amelioration of energy supply to the cells. These beneficial effects show great promise in its application as a treatment option for women facing infertility disorders.
\end{abstract}

Keywords: Assisted reproductive technology, Acetyl-L-carnitine, Antioxidants, Female fertility, In vitro fertilization, L-carnitine, Oocyte quality

\section{Background}

The revolution of modern day reproductive biology research and assisted reproductive technology (ART) are promising to provide a more exhaustive description of the effects of metabolic supplementation on infertility. To date, thousands of supplements have been proposed to mitigate the outcomes of reproductive disorders, but most of them have ended up having several side-effects on other systems [1]. In order to combat this, reproductive biologists are currently searching for some supplements, or combination of supplements to fight against the problems of infertility. In this aspect, mitochondrial metabolism of both the male and female germ cells exert a crucial role [2]. Mitochondrial nutrient supplementation is also reported to be effective in many cases [3].

Levocarnitine or L-carnitine (LC) is a biologically active stereoisomer of 3-carboxy-2-hydroxy-N, N, N-trimethyl-

\footnotetext{
* Correspondence: agarwaa@ccf.org

${ }^{1}$ American Center for Reproductive Medicine, Cleveland Clinic, Glickman Urological and Kidney Institute, Mail Code X-11, 10681 Carnegie Avenue, Cleveland, OH 44195, USA

Full list of author information is available at the end of the article
}

1-propanaminium. It exists as a highly polar, small zwitterion (an ion that while electrically neutral, carries both a positive and a negative electrical charge in different parts of the molecule, as seen in certain amino acids and protein molecules) [4]. LC is reported to have benefits in the management of infertility $[5,6]$. The impact of $\mathrm{LC}$ on male infertility is now well documented. It has been reported to be concerned with epididymal maturation of spermatozoa [7]. LC serves as an intra-mitochondrial vehicle for the acyl group, which in the form of acyl-CoA acts as a substrate for the oxidation process, producing energy for sperm respiration and motility $[7,8]$. It has also been reported to ameliorate the effects of reactive oxygen species (ROS) and free radical-induced oxidative stress (OS) and minimizing pathological disorders of sperm, like adenosine triphosphate (ATP) depletion leading to insufficient axonemal phosphorylation, lipid peroxidation as well as loss of motility and viability $[9,10]$. As LC has been reported to act as a potent antioxidant with very less sideeffects, researchers are now considering its implementation as a treatment for female infertility $[5,11,12]$. It is well known that OS also affects female reproduction in 
various ways, including lipid peroxidation of oocytes [13], fertilization and embryo development in animals [14].

Similarly, acetyl-L-carnitine (ALC), the primary acetyl ester of LC has been reported to have beneficial impacts on reproductive functions through its antioxidative effects $[7,8,15]$. ALC plays an essential role in intermediary metabolism, acting as a donor of acetyl groups and facilitating the transfer of fatty acids from cytosol to mitochondria during beta-oxidation in animals [15]. ALC has also been reported to exert cholinomimetic effects and to modulate the gamma-amino butyric acid (GABA) system. Since it is abundant in hypothalamus, it can affect the neuronal activity and thus hypothalamopituitary gonadal (HPG) axis to exert its impact on female reproduction [16].

To date, many research studies have already been carried out in human $[11,12,17,18]$ and animal models $[16,19-21]$ using carnitines to treat female infertility as well as to improve reproductive performance. It has also been used in ART in an attempt to solve similar problems [22, 23].

This review summarizes the effects of both LC and acetyl-L-carnitine (ALC) on female fertility with detailed scrutiny of the reports published till date. It provides a glimpse of human, animal and in vitro experimental studies carried out to solve the problems of female infertility. It also provides its possible mechanism of actions when supplemented individually or in combination with other nutrients.

\section{L-carnitine and acetyl L-carnitine: Physiological actions}

$\mathrm{LC}$ is a small water-soluble molecule that plays an enormous role in normal physiology. It was first isolated from bovine muscle in 1905 by two Russian scientists [24], and only the L-isomer was found to be bioactive [4]. In mammals, ingested LC is absorbed from the small intestine via active transport and passive diffusion [25]. $\mathrm{LC}$ is then incorporated into the total body carnitine pool that includes uncharged LC, and short chain carnitine esters (acylcarnitines) such as ALC and propionyl $\mathrm{L}$-carnitine (PLC). LC is also synthesized in the liver and kidneys via methylation of L-lysine [26]. A strict vegetarian diet may lead to deficiency of LC since red meat is the richest source of lysine. The accumulation of LC occurs in liver, skeletal muscle, heart, brain and testis [27]. The body tissue distribution studies show a very high concentration of LC in mature spermatozoa and luminal fluid of cauda epididymis [26]. Under physiological conditions, the carnitine pool (LC and ALC) remains in equilibrium because of the actions of local transferases and tubular reabsorption in the kidney [28].

Carnitines belong to one of the special classes of nutrients called 'quasi-vitamins' or 'conditionally-essential' nutrients [29]. LC intake is widely regarded as one of the most effective ways to promote endurance, burn fat, and shorten post-workout recovery [27]. In peripheral tissues, it helps in $\beta$-oxidation by transporting medium and long chain fatty acids into the mitochondria [30]. It is also important in maintaining cell membrane stability through its involvement in acetylation of membrane phospholipids and amphiphilic actions [31, 32]. LC also prevents DNA damage induced by the detrimental actions of free radicals [33]. It also functions as a stabilizer of a low acetyl CoA/CoA concentration ratio and as an acetyl store to supply energy in carbohydrate and lipid metabolic pathways [34] (Fig. 1).

\section{L-carnitine and acetyl L-carnitine in female fertility}

Several research studies have been carried out till date in human patients, animal models and in ART settings to investigate the effectiveness of $\mathrm{LC}$ and ALC in the improvement of female fertility $[5,22]$.

\section{L-carnitine or acetyl L-carnitine - which carnitine is suitable for the treatment of female infertility?}

Though a minute functional difference between LC and ALC has been reported, both are used in reproductive biology research to improve mitochondrial functions to treat infertility $[5,8,9]$. ALC is used most often associated with the improvement of antioxidant/anti-aging effects, while LC is commonly used to improve the body's ability to oxidize fat cells which assists in the production of energy and burning fat [27]. During oocyte development, it has been reported that the cumulus-oocyte complex (COC) plays an essential role in lipid metabolism and energy production. Thus, in oocytes, maintenance of proper lipid oxidation with/without a minimum production of free radicals is crucial to preserve its quality [30]. Though it is well documented that both forms of carnitine possess antioxidant properties [10], it has been suggested in some reports that ALC is more effective in combating ROS-induced oxidative damage compared to LC [15]. Thus, studies focusing on antioxidant defense-mediated improvement of female fertility preferentially utilize ALC, whereas, studies demonstrating improved lipid metabolism-induced enhancement of oocyte quality, and thereby fertility, tend to use LC. Other acylcarnitines are also used in reproductive biology research, but to a lesser extent [35]. In 2013, Varnagy et al. reported the profiling of several acylcarnitines in the serum and follicular fluids of women undergoing IVF. They provided suggestive evidence that in IVF patients with better reproductive potential (higher number of oocytes and/or viable embryos), the LC/acylcarnitine pathway appears to be upregulated while the endogenous carnitine pool is diminished, which consequently improves oocyte quality [35]. In the following sections, 


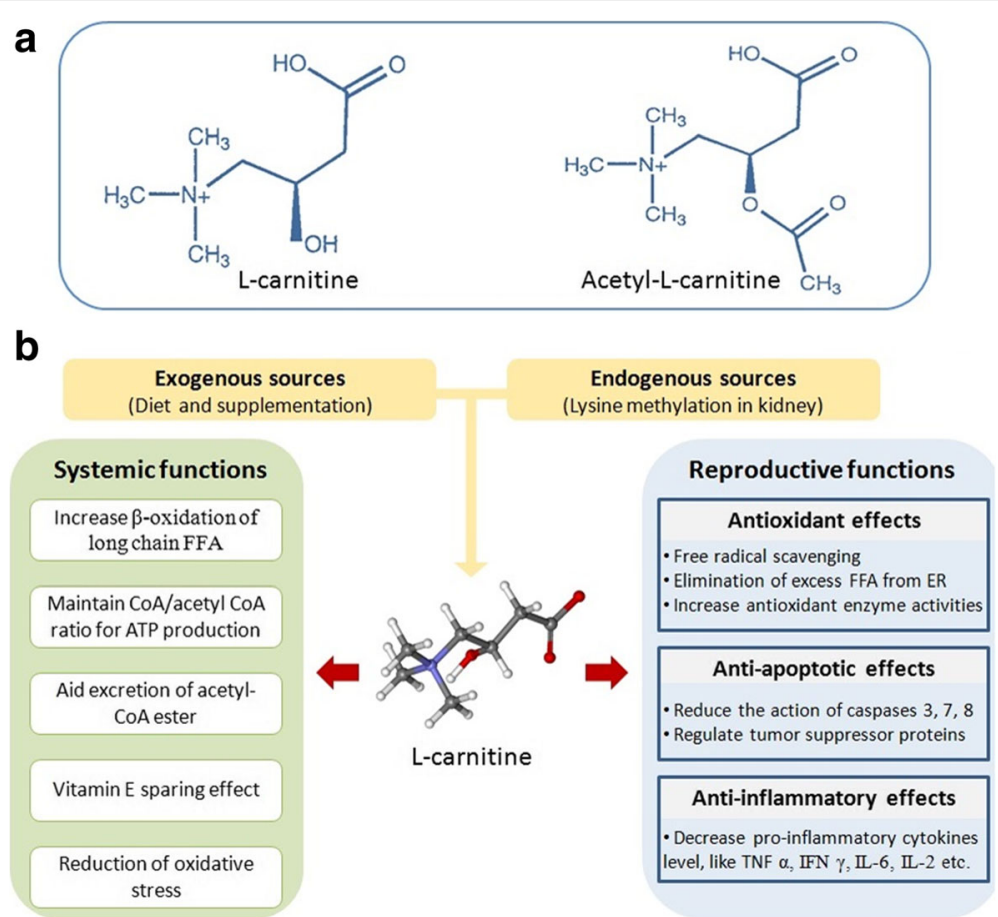

Fig. 1 (a) Molecular structures of L-carnitine and acetyl-L-carnitine, (b) systemic and reproductive functions of L-carnitine. CoA, coenzyme A; ER, endoplasmic reticulum; FFA, free fatty acid; IFN, interferon; IL, interleukin; TNF, tumor necrosis factor

we will provide evidence of LC and/or ALC supplementation and their role in female fertility.

\section{Human studies}

Most of the human experiments were carried out using $\mathrm{LC}$ as a supplement to alleviate/combat the problem of female infertility $[11,18,36]$ (Table 1 ). Several studies found that both LC and ALC supplementation improves disorders such as polycystic ovary syndrome [12], endometriosis [19] and amenorrhea [17]. Carnitines are reported to increase gonadotropins and sex hormone levels as well as improve oocyte health [17]. However, the effects of LC on endometriosis are still a matter of debate $[19,29,37,38]$. The possible mechanistic pathways through which LC could exert its effects on endometriosis will be discussed in a subsequent section.

\section{Carnitine and PCOS}

Polycystic ovary syndrome (PCOS) is a common female reproductive endocrinopathy. The main pathophysiological mechanisms underlying this syndrome include obesity, insulin resistance and hyperinsulinemia. Samimi and colleagues found that LC supplementation $(250 \mathrm{mg}$ per day orally for 12 weeks) lead to significant reduction in body weight, BMI, waist and hip circumference respectively as well as improved glycemic control in women with PCOS (mean age $24.8 \pm 5.5$ years) [12]. This study indicated that LC supplementation improves
PCOS by decreasing blood glucose levels and opposing insulin resistance [12], which could perhaps be attributed to LC-induced increase in beta-oxidation of fatty acids and basal metabolic rates [39].

Women with PCOS also have an imbalance between male and female hormones as their ovaries tend to produce androgens in excessive amounts. One study suggested that hyperandrogenism and/or insulin resistance in the non-obese women with PCOS may be associated with decreased total serum LC levels [36]. Fenkci's group had measured the serum total LC levels in non-obese women with PCOS ( $n=27$; aged between 16 to 37 years) in comparison to that of healthy adult women $(n=30)$. They demonstrated these PCOS patients have significantly lower total LC $(40.5 \pm 5.7 \mu \mathrm{mol} / \mathrm{L}$; in control: 91.1 $\pm 15.2 \mu \mathrm{mol} / \mathrm{L}$ ), but higher levels of dehydroepiandrosterone (DHEA), testosterone, luteinizing hormone (LH), low-density lipoproteins (LDL) and fasting insulin compared to healthy women [36].

Another common feature of PCOS is chronic anovulation. The standard approach to treat women with anovulatory infertility, secondary to PCOS, is to administer clomiphene citrate to induce ovulation. However, some women do not ovulate despite receiving increasing doses of clomiphene citrate, and are therefore considered to be clomiphene citrate-resistant. In a single center, double blinded, randomized controlled clinical trial, Ismail et al. studied the effect of LC 


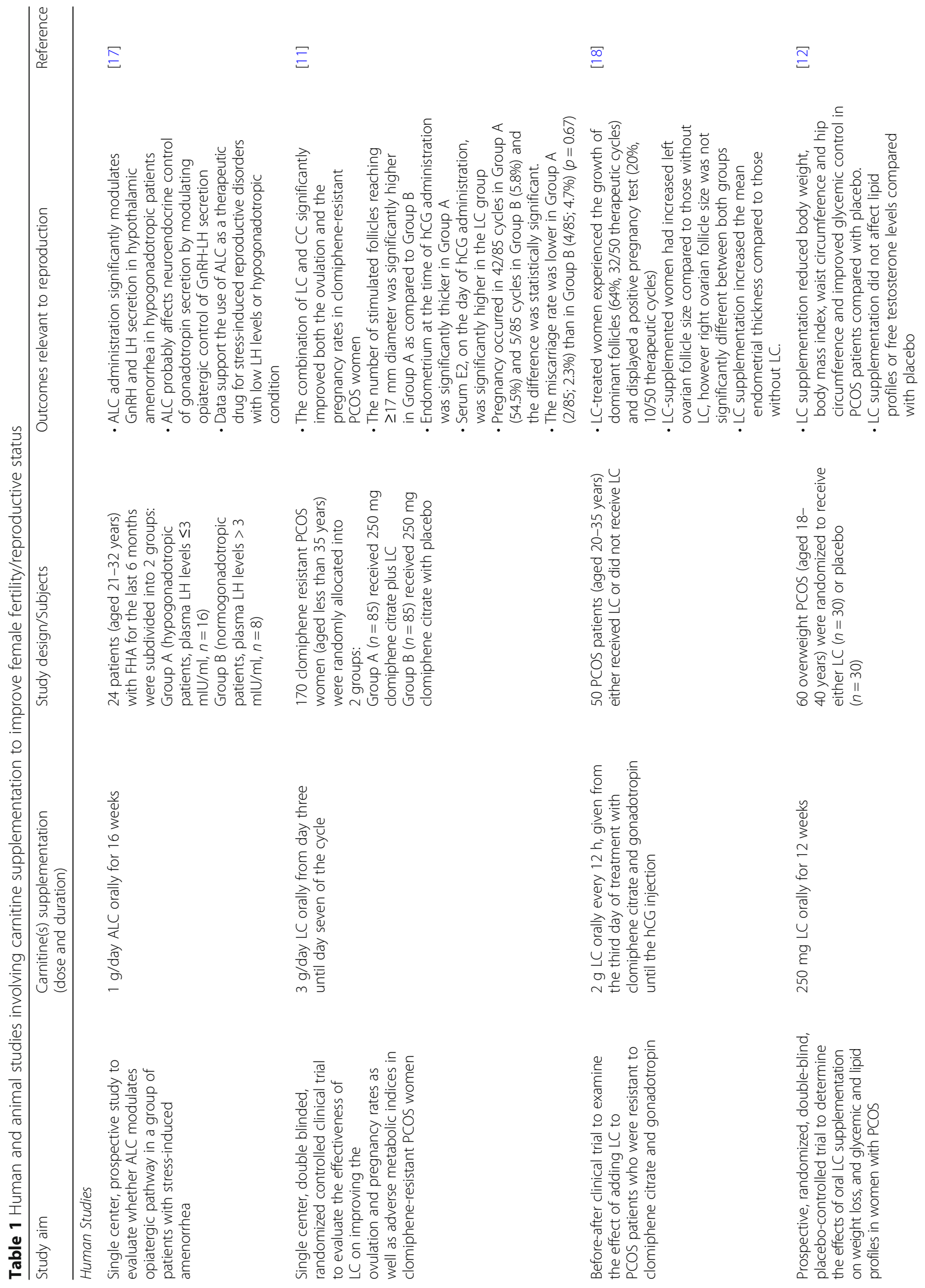




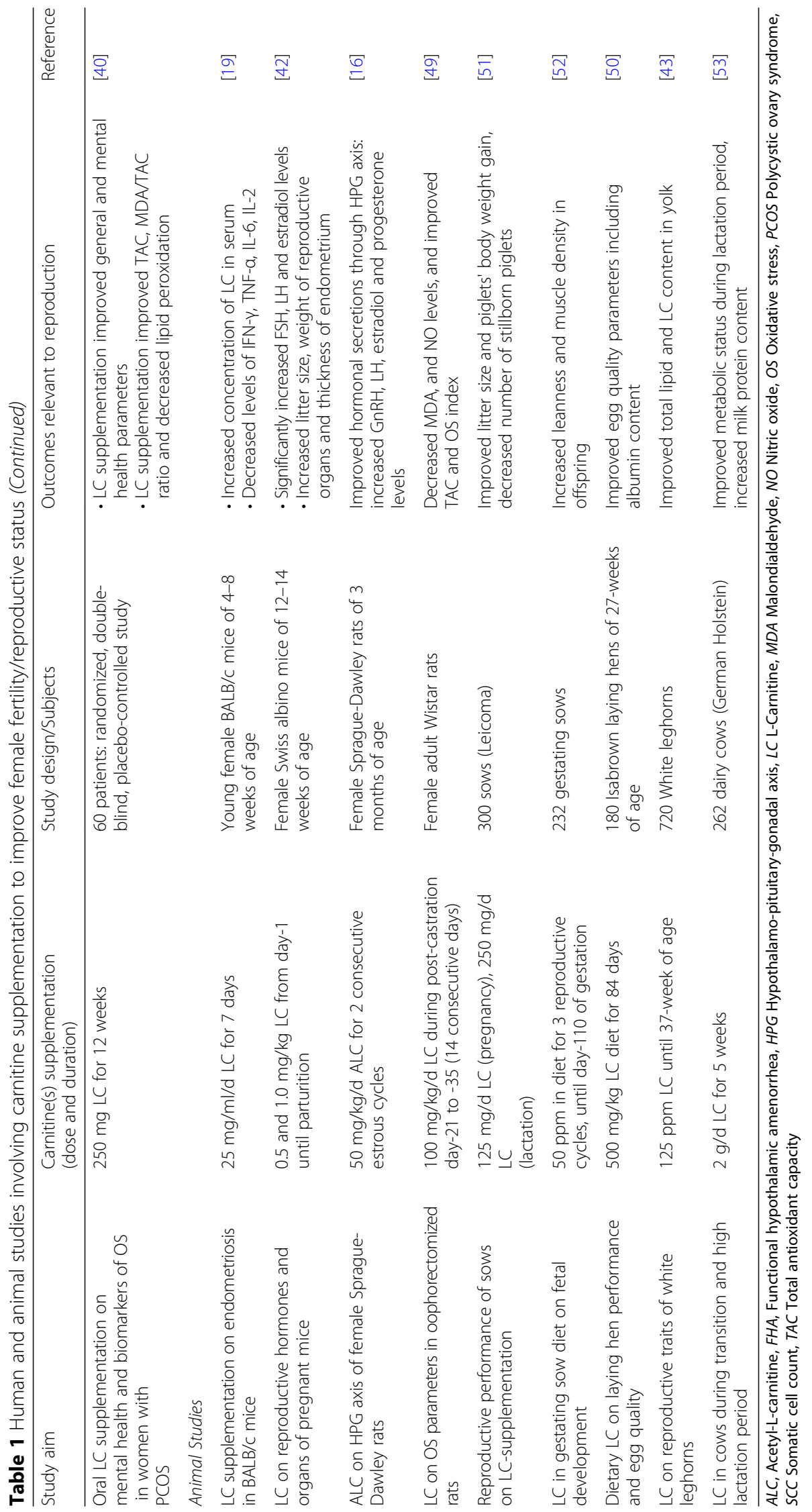


supplementation on clomiphene-resistant women with PCOS. All subjects received $250 \mathrm{mg}$ clomiphene citrate daily from day- 3 until day- 7 of the cycle. In addition, women in the treatment arm $(n=85)$ were supplemented daily with $3 \mathrm{~g}$ of LC orally (day-3 until day of first positive pregnancy test), while those in the control arm $(n=85)$ received a placebo. Follicular maturation was monitored using transvaginal ultrasonography on all patients on day-7 and day-9, and subsequently adjusted according to individual response [11].

Ismail's group found that LC supplementation along with clomiphene citrate treatment improved both ovulation $(64.4 \%$ vs. $17.4 \% ;<0.0001)$ and pregnancy $(51.5 \%$ vs. $5.8 \% ; p<0.0001)$ rates in clomiphene-resistant women with PCOS. LC supplementation seemed to improve the number and rate at which the stimulated follicles developed (to a diameter of $\geq 17 \mathrm{~mm}$ for induction of ovulation), increase beta-oxidation and oocyte maturation as well as increase serum levels of both estradiol $\left(E_{2}\right)$ and progesterone. LC supplementation not only improved reproductive health, but also enhanced the patients' lipid profile and body mass index (BMI) [11].

A typical alternative treatment to induce ovulation in clomiphene citrate-resistant PCOS patients is gonadotropin therapy. However, some women with PCOS fail to respond to both these treatments. Latifian et al. studied the effects of LC on 50 infertile women with PCOS who were both clomiphene- and gonadotropin-resistant. These women (mean age $27.98 \pm 4.61$ years) showed improvement following LC supplementation, which was given $2 \mathrm{~g}$ orally every $12 \mathrm{~h}$ (from the third day of the ovarian stimulation cycle onwards until the HCG injection). The LC-treated women in this study experienced the growth of dominant follicles $(64 \%, n=32)$ and displayed a positive pregnancy test $(20 \%, n=10)$. Moreover, LC was observed to increase the mean endometrium thickness as well as to inculcate positive changes in the left ovarian follicle size [18].

Not only does LC supplementation improve reproductive parameters in PCOS patients, but it can also confer positive effects on other health parameters in these women. This was demonstrated in a recent study whereby oral LC supplementation (250 mg for 12 weeks) among patients with PCOS improved total antioxidant capacity (TAC), decreased lipid peroxidation and enhanced general and mental health parameters [40].

\section{Carnitine and functional hypothalamic amenorrhea}

Functional hypothalamic amenorrhea (FHA) is a form of hypogonadotropic hypogonadism that results from an aberration in the pulsatile release of hypothalamic gonadotropin-releasing hormone $(\mathrm{GnRH})$, which causes decreased gonadotropin release leading to reduced estradiol production in the ovary [41]. ALC administration (1 g/day orally for 16 weeks) in patients suffering from FHA ( $n=24$, age range 21 to 32 years) was found to increase LH levels by counteracting certain neuroendocrine pathways that have an inhibitory effect on the reproductive axis [17]. Genazzani and co-workers proposed that ALC acts through the opioidergic pathway and alters protein/hormone functions by acetylating - $\mathrm{OH}$ groups in amino acids like serine, threonine or tyrosine, thereby improving their functions. They concluded that ALC has positive therapeutic effects on the reproductive axis in hypogonadotropic women with FHA and improves the condition by acting through the HPG axis [17].

\section{Animal studies}

Numerous research studies have been carried out in animal models (murine and farm animals) to investigate how LC and ALC improve female reproductive functions [16, 19, 21, 42-44] (Table 1). Carnitines have been showed to have beneficial impacts in most of the studies involving PCOS, endocrine disorders and other cases of infertility. However, as alluded earlier, carnitines appear to possibly exert mixed effects on endometriosis [19, 29, 37, 38].

\section{a) Mice and rat models}

\section{Carnitine, cytokines and immune response}

Despite the aforementioned beneficial effects of LC and ALC treatment on female fertility, Dionyssopoulou et al. found that carnitine supplementation modified the production of various cytokines, such as interferon- $\gamma$, tumor necrosis factor- $\alpha$, interleukins-2, $-4,-6$, vascular endothelial growth factor, granulocyte-macrophage colony stimulating factor, and insulin-like growth factor-1 in serum and peritoneal fluid as tested using the immunofluorescence or ELISA technique [19]. Furthermore, carnitine treatment altered the percentage of immune cells (macrophages, $\mathrm{T}$ cells, $\mathrm{CD}^{+}$and $\mathrm{CD} 8^{+}$ cells) in peritoneal exudates and uterine cells. Immune modifications such as these as well as the presence of cytokines and growth factors in the peritoneal cavity may contribute to the development of endometriosis. The potential role of prostaglandins (PG), including that of $\mathrm{PGE}_{1}$ and $\mathrm{PGE}_{2}$, are directly associated with inflammation and could affect the function of immune cells. It was found that while inhibition of $\mathrm{PGE}_{1}$ further increased the levels of certain cytokines in serum and peritoneal fluid [45], inhibition of $\mathrm{PGE}_{2}$ reversed these values toward that of control [46]. Thus in presence of $\mathrm{LC}$, it was suggested that $\mathrm{PGE}_{2}$ plays a role in the mechanistic pathway leading to endometriosis, while $\mathrm{PGE}_{1}$ may potentially be involved in suppressing the production of immune cells and inflammatory response [29]. 
Carnitine and the HPG axis

In 1992, Krsmanovic et al. examined the impact of ALC (50 mg/kg/day for a month) on the HPG axis in female rats and found that serum LH and prolactin levels were increased during the proestrous and estrous phases, while serum $E_{2}$ levels were increased during the estrous phase of the cycle. They have also noted an increase in uterine weight during both the proestrous and estrous phases of ALC-treated animals. Release of basal $\mathrm{GnRH}$ was found to be increased during the proestrous and diestrous I in hypothalamic slices of ALC-treated rats, which could mean that ALC stimulates the secretory activity of GnRH-producing hypothalamic neurons. In contrast, no alteration in pituitary functions was detected following ALC treatment in vitro. From these results, it was concluded that ALC may act through the HPG axis and cause gonadotropin release and this action is dependent on the cycle stage [16].

Carnitine and oocyte quality

Virmani et al. reported in 2015 that treatment of mice with both LC ( $0.4 \mathrm{mg} / \mathrm{mouse})$ and ALC (0.12 mg/mouse) resulted in increased number of mature oocytes and less degradation of oocytes. They concluded that LC and ALC co-treatment showed better response in maintaining the quality and quantity of oocytes in mice. In females, an age-related decline in the number and quality of follicles and oocytes have already been documented [47]. Aging and ROS affects many biochemical pathways of developing oocytes that may produce a deleterious impact on oocyte health and in this aspect, LC supplementation has showed some beneficial roles. Christiana's group investigated another potential effect of LC through their study in which young BALB/c mice were given LC supplementation $(2.5 \mathrm{mg} /$ day/mouse for 7 days), superovulated and then mated with healthy males. They showed that 7 day-LC administration alters the lipid body content in pre-implantation embryos and did not result in live births in these females. This is because lipid body content is an important contributory factor towards healthy oocyte and embryo development and therefore its alteration may lead to infertility [37]. Conversely, a recent report by Virmani et al. (2017) showed that supplementation of carnitines (LC $0.4 \mathrm{mg} / \mathrm{mouse}+$ ALC $0.12 \mathrm{mg} / \mathrm{mouse}$ ) to 8 -week-old female CD1 mice not only improved oocyte formation but also increased the number of live birth in superovulated mice [48].

\section{Carnitine and pregnancy-related parameters}

Fakhrildin and Flayyih reported an improvement in weight of the reproductive organs (ovaries, uterine horns, vagina) and endometrial thickness, litter sizes as well as serum LH, FSH and E2 levels in pregnant mice (Swiss albino strain females aged between 12 to 14 weeks) given 0.5 and $1.0 \mathrm{mg} / \mathrm{kg} \mathrm{LC}$ compared to the control group. As the parameters measured did not differ significantly between the two LC doses used, the study concluded that a low dose of LC was sufficient to render positive effects on pregnancy and offspring outcomes in pregnant mice [42].

Carnitine and oxidative stress

Canbolat and co-worker's study investigated the antioxidant property of LC (100 and $500 \mathrm{mg} / \mathrm{kg} /$ day) on oxidative stress parameters (nitric oxide $(\mathrm{NO})$, malondialdehyde, total antioxidant status, total oxidative stress (OS), and OS index in the kidney, liver and heart, as well as sera of bilateral oophorectomized rats. They have reported LC exhibits antioxidant effects in different tissues with less NO production, lipid peroxidation and OS index when supplemented with $500 \mathrm{mg} / \mathrm{kg} /$ day LC intraperitoneally for 14 consecutive days in surgically menopausal rats [49].

b) Farm animal models

Several studies have also looked into the effects of carnitine supplementation on improving the rate of ovulation and fertilization [20], egg quality [44, 50], number of litters born $[20,51]$ etc., of farm animals such as pigs, chickens and cows.

\section{Carnitine and ovulation and fertilization rates}

Samland et al. examined the effect of dietary supplementation of LC (200 ppm) on the ovulation and fertilization rate of gilts (young female adult breeding pigs that have not yet farrowed). After two weeks, the gilts fed with added carnitine were found to have increased rate of ovulation, but decreased fertilization rate of the recovered embryos. However, the report did not offer an explanation as to the possible cause of decreased fertilization rates despite increased ovulation rates in this group of gilts [20].

Carnitine, embryo development and post-natal growth

Zhai and co-workers examined the effect of dietary supplementation of LC (125 ppm) on the reproductive traits of male and female White Leghorn chicken. They reported that the yolk of fresh eggs retrieved from LChens that were inseminated with semen from roosters consuming either the control or the LC-diet contained higher concentrations of LC but decreased hatchling yolk sac weights and yolk sac lipid content compared to that of control hens. This suggests that LC encourages fat utilization in the developing embryos [43].

In another study using gestating sows (mature female pigs that have farrowed at least once before the current gestation), Musser et al. demonstrated that a $50 \mathrm{ppm} \mathrm{LC}$ supplementation in gestation sow diet improved muscle fiber development by increasing the leanness and muscling of the fetal piglet. These changes could perhaps improve postnatal growth in the piglets [52]. 


\section{Carnitine and egg quality}

In another study on the performance and egg quality parameters of Brown egg-type laying hens, Corduk and Sarica reported that supplementation of $500 \mathrm{mg}$ LC per $\mathrm{kg}$ of low energy diets containing either sunflower or palm oil increases the eggshell breaking strength. Moreover, the addition of LC into normal diet containing palm oil increased the albumen index (calculated from the albumen height, length and weight) of the eggs [50]. Greater eggshell breaking strength and a higher albumen index indicates higher egg quality.

\section{Carnitine and milk production and quality}

Pirestani and colleagues evaluated the effect of LC supplementation $(50 \mathrm{~g} /$ day/cow $)$ for 40 days on milk somatic cell count (SCC) (as a measure of the milk quality) and several reproductive indices in Holstein dairy cattle. They reported a significant reduction in milk SCC (indicating less mastitis or enhanced udder immunity and therefore better quality of milk) and improvement in the reproductive indices. In addition, the study found that a combination of LC and a vitamin-like essential macronutrient, choline (60 g/day/cow) further reduced milk SCC and improved the reproductive indices [21].

In another study on German Holstein dairy cows, Scholz's group showed that supplementation with $2 \mathrm{~g}$ of $\mathrm{LC} /$ cow (contained in $10 \mathrm{~g}$ of a rumen-protected product) for three months improved metabolic health during the critical periods of transition and high lactation and showed a trend of improving milk production during the initial 2months after calving. Furthermore, LC-supplemented cows had a lower insemination index and increased conception rate compared to controls [53].

\section{In vitro studies and assisted reproduction}

Following reports on the antioxidant properties of LC and ALC and its beneficial effects on female fertility, carnitines have been used in in vitro studies focusing on the improvement of oocyte health and maturation, embryo development as well as in assisted reproduction $[54,55]$ (Table 2). In the last two decades, a good number of studies have been published that showcase the impact of carnitine supplementation on female fertility. Of late, it has been used to minimize ROSmediated delayed embryonic development in culture medium, high DNA fragmentation and development of morphologically abnormal blastocysts after prolonged culture $[6,23,56]$.

During in vitro fertilization (IVF) procedures, embryo fragmentation due to apoptosis is a common occurrence that is well documented. Nonetheless, supplementation of culture medium with LC may confer protection to the developing immature cells. Pillich et al. have shown that ALC supplementation (0.3, 0.6 and $1.2 \mathrm{mM}$ for $5 \mathrm{~h}$ and $24 \mathrm{~h}$ ) in mouse fibroblast culture media stabilizes the mitochondrial membrane, increases energy supply to the organelle and protects the developing cell from apoptosis through the mitochondrial pathway [57]. In another laboratory, Abdelrazik and colleagues looked into the optimal dose of $\mathrm{LC}$ that is required for blastocyst development of mouse embryos. They have showed that 0.3 and $0.6 \mathrm{mg} / \mathrm{mL}$ of LC possesses antiapoptotic effects as well as increased the rate of blastocyst development [33].

A marked increase in TNF- $\alpha$ concentration in granulosa cell cultures of women with endometriosis has been demonstrated [58-61]. Studies have also shown that increased levels of TNF- $\alpha$ restrict inner cell mass and trophectoderm proliferation in mouse blastocyst. At a concentration of $50 \mathrm{ng} / \mathrm{mL}$, TNF- $\alpha$ was found to affect protein synthesis in mouse embryos in both morula and blastocyst stages $[62,63]$. However, LC at the doses of 0.3 and $0.6 \mathrm{mg} / \mathrm{mL}$ were able to neutralize the antiproliferative effects on TNF- $\alpha$. LC supplementation in embryo culture medium also decreased DNA damage during development [6].

These observations were reaffirmed by Zare and coworkers who used the same doses $(0.3$ and $0.6 \mathrm{mg} / \mathrm{mL})$ of LC supplementation during in vitro maturation of immature $\mathrm{BCB}+$ (Brilliant Cresyl Blue positive) oocytes. LC-treated oocytes demonstrated an improved preimplantation developmental competence (quality) after IVF, which is probably due to LC-induced improvement in the cytoplasmic and nuclear maturation of immature oocytes. LC at the doses used also exhibited an antioxidative effect during embryo development by reducing ROS levels in the maturation medium [64].

In another study, Mansour et al. used the same dose $(0.6 \mathrm{mg} / \mathrm{mL})$ of LC to demonstrate the protective effects of LC on oocytes and embryos against the toxic effects of peritoneal fluid in women with endometriosis. They have showed that peritoneal fluid of patients with endometriosis which was supplemented with LC had decreased apoptosis levels in the embryos and improved oocyte microtubular and chromosomal structure [38]. Bareh has also reported that LC-induced improvements in cytoskeleton could lead to reduced aneuploidy rates in an animal model [65].

In 2013, Phongmitr et al. added LC (0.3, 0.6 and $1.2 \mathrm{mg} / \mathrm{mL}$ ) to culture media containing swamp buffalo oocytes and noted an improved nuclear maturation rate with a maximum number of metaphase II (MII) oocytes in the $0.3 \mathrm{mg} / \mathrm{mL}$ LC-supplemented group [66]. Moawad's group later showed that LC supplementation $(0.6 \mathrm{mg} / \mathrm{ml}$ or $3.72 \mathrm{mM})$ during vitrification/warming and in vitro maturation of germinal vesicle stage-oocytes increased the proportions of oocytes with normal MII spindles. They also reported that LC supplementation causes increased oxidative activity of mitochondria in 


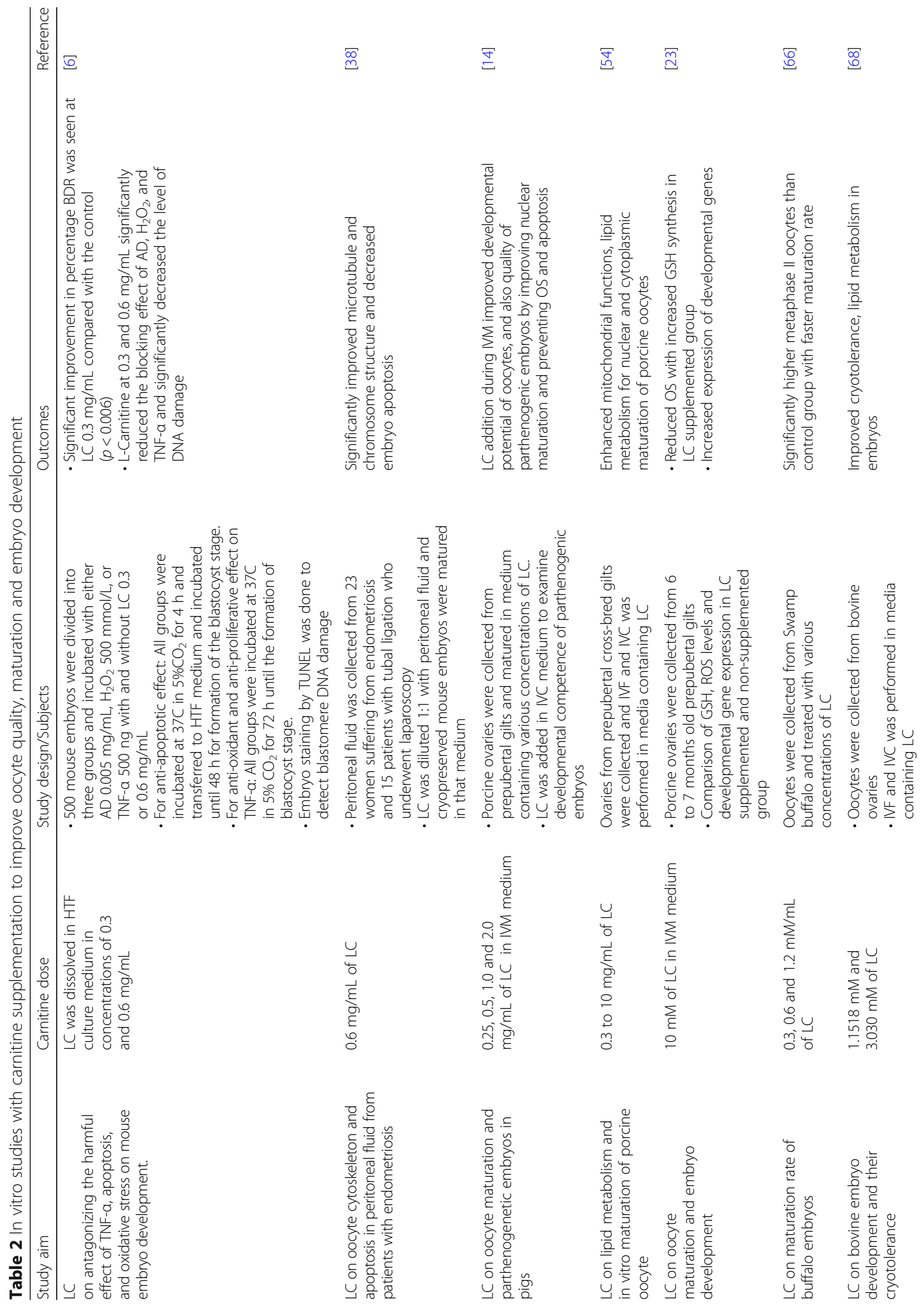




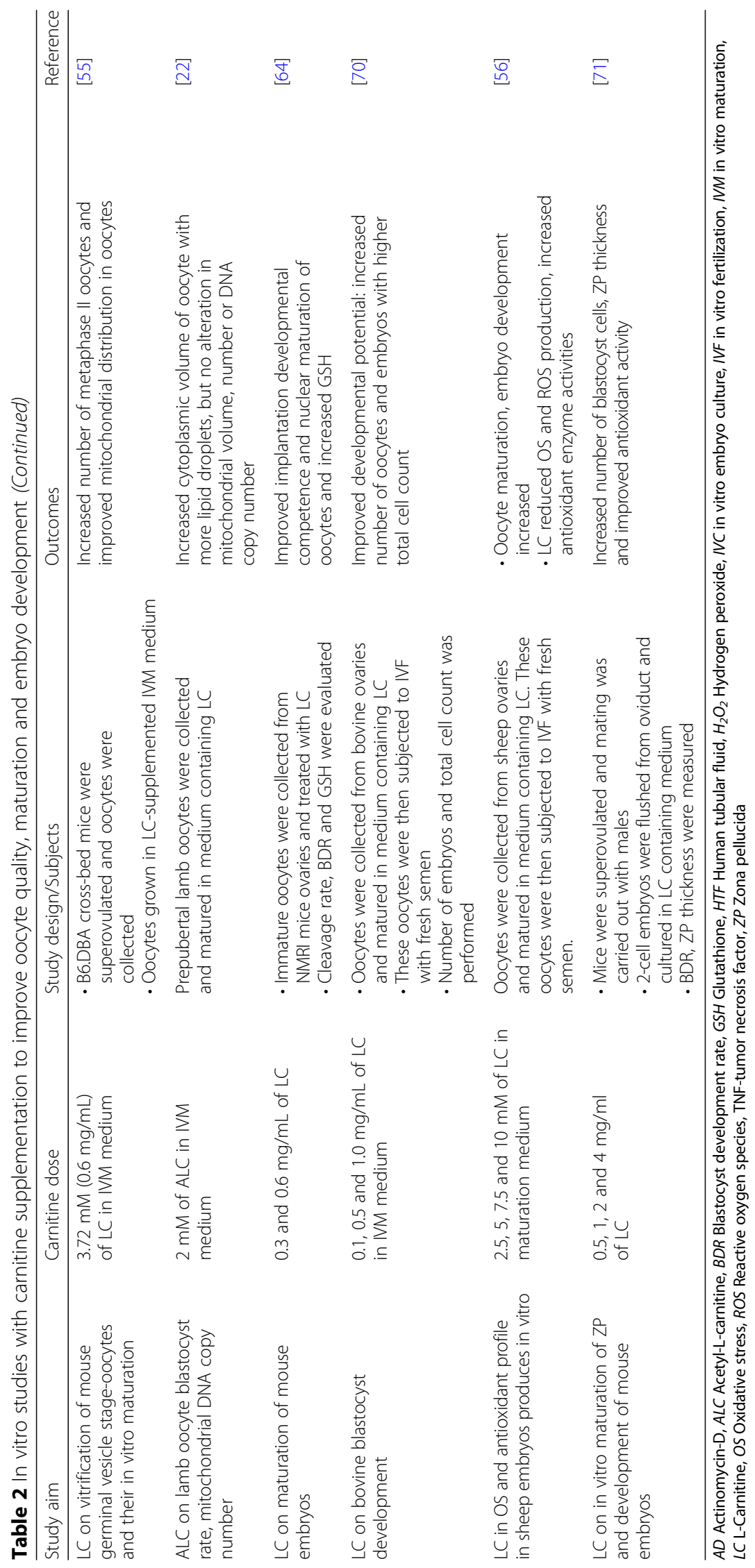


the resultant MII oocytes without increasing the ATP levels in MII oocytes [55].

Ghanem and co-workers reported similar observations of increased antioxidant activity and improved blastocyst quality by way of higher embryo development rate and fewer number of apoptotic cells after supplementing LC $(1.5 \mathrm{mM}$, equivalent to $0.3 \mathrm{mg} / \mathrm{mL}$ ) in culture media of bovine blastocyst during the pre-implantation stage [67]. Similar studies conducted earlier have also shown higher counts of total cells $[68,69]$ and lower apoptotic cells [69] in bovine embryos cultured in $0.3 \mathrm{mg} /$ $\mathrm{mL}$ L-carnitine.

Manzano's group investigated the role of L-carnitine supplementation in the maturation of bovine oocytes and pre-implantation development of embryos. They reported improved developmental potential up to the blastocyst stage with higher blastocyst formation rate and increased total cell count and activity when the oocytes were matured in culture media added with 0.1$0.5 \mathrm{mg} / \mathrm{mL}$ LC. In a subsequent experiment, supplementation of the resulting zygotes with the same dose of LC in modified synthetic oviductal fluid medium displayed a higher blastocyst total cell count, but similar blastocyst formation rates as that of control [70].

Khanmohammadi and colleagues evaluated the effect of LC $(0.5 \mathrm{mg} / \mathrm{mL})$ supplementation on several indicators of embryo development and blastocyst quality such as thickness of zona pellucida, hatching rate and number of blastocyst cells. At a concentration of $0.5 \mathrm{mg} / \mathrm{mL}$, LC exerted antioxidant properties, along with an enhancement of mitochondrial lipid metabolism to increase blastocyst cell number, blastocyst expansion and zona pellucida thinning, all of which promotes blastocyst quality leading to successful hatching and implantation. Conversely, LC at high concentrations $(4 \mathrm{mg} / \mathrm{ml})$ had a toxic effect on in vitro embryo development and blastocyst quality [71].

\section{Possible mechanisms of action of LC Direct effects}

LC has been reported to maintain cellular energy [34], reduce oxidative stress [72] and minimize cell death by apoptosis [33], which are necessary for proper oocyte growth and maturation of blastocyst. As discussed earlier, the cumulus-oocyte complex (COC) and its lipid metabolism are one of the prime regulators of oocyte maturation [73]. LC helps in the metabolism of COC lipids by transferring fatty acids into the mitochondria and by facilitating $\beta$-oxidation [30]. LC is taken up by the tissues via the electrogenic force of the voltagegated $\mathrm{Na}^{+}$-channels. It uses the $\mathrm{Na}^{+}$-driven $\mathrm{LC} /$ organic cation transporter-2 (OCTN-2) for its transport into the oocytes [74].
In the oocytes, LC gets converted to ALC by carnitine palmitoyltransferase-I (CPT-I) in the outer mitochondrial membrane and CPT-II helps in the regeneration of carnitine from acyl-carnitine after the translocation of long chain fatty acids into the mitochondrial matrix [31]. Within the oocyte, LC plays a significant role in ER, mitochondria as well as in the ooplasm. In the mitochondria, LC is converted to ALC, and balances the acetyl $\mathrm{CoA} / \mathrm{CoA}$ ratio to maintain glucose metabolism through the TCA cycle, yielding a higher energy production [34]. LC helps in minimizing the concentration of pyruvate which prevents entry into the TCA cycle to curtail energy production (Fig. 2).

In the mitochondria, LC also scavenges ROS through its antioxidant property. It transports palmitate and other long chain fatty acids to the mitochondria to facilitate their utilization through $\beta$-oxidation [5]. In the ER, it decreases the concentration of palmitate by transferring it to the mitochondria or by eliminating it from which it may cause lipotoxicity of the oocytes through oxidative stress [34]. It is reported that higher ROS levels decrease maturation by affecting the $\mathrm{COC}$, and also decreases embryo development and blastocyst fragmentation [75]. LC also promotes cellular proliferation and decreases apoptosis by inhibiting TNF- $\alpha$ and other anti-proliferative agents [33]. In endometriosis, LC has been claimed to possess dual effects through the uterine secretion of prostaglandins. LC treatment has been shown to increase the production of both $\mathrm{PGE}_{1}$ and $\mathrm{PGE}_{2}$. It was suggested that $\mathrm{PGE}_{1}$ confers protection against endometriosis by attenuating the secretion of TNF- $\alpha$, IFN- $\gamma$ and interleukins (IL-2, IL-4 and IL-6), while $\mathrm{PGE}_{2}$ induces cytokine release and thus endometriosis through its apoptotic and inflammatory functions $[19,46]$. However, further robust studies are required to corroborate the findings regarding the role of LC on endometriosis.

Thus, in summary, free LC or ALC serves three important functions in oocytes through its direct action: first, it increases energy production by transferring palmitate into mitochondria and maintaining acetyl $\mathrm{CoA} / \mathrm{CoA}$ ratio; secondly, it reduces oxidative stress and lipotoxicity by scavenging free radicals and removing excess palmitate from the ER, and finally it promotes oocyte growth and maturation by decreasing the rate of apoptosis.

\section{Indirect effects}

LC and ALC have also been reported to affect the HPG axis to promote reproductive hormone secretion $[16,17,76]$. It has been known that among the neural centers, LC's concentration is highest is in the hypothalamus [77]. In the hypothalamus, LC has been reported to decrease neuronal cell death and damage associated with aging [78] by its 


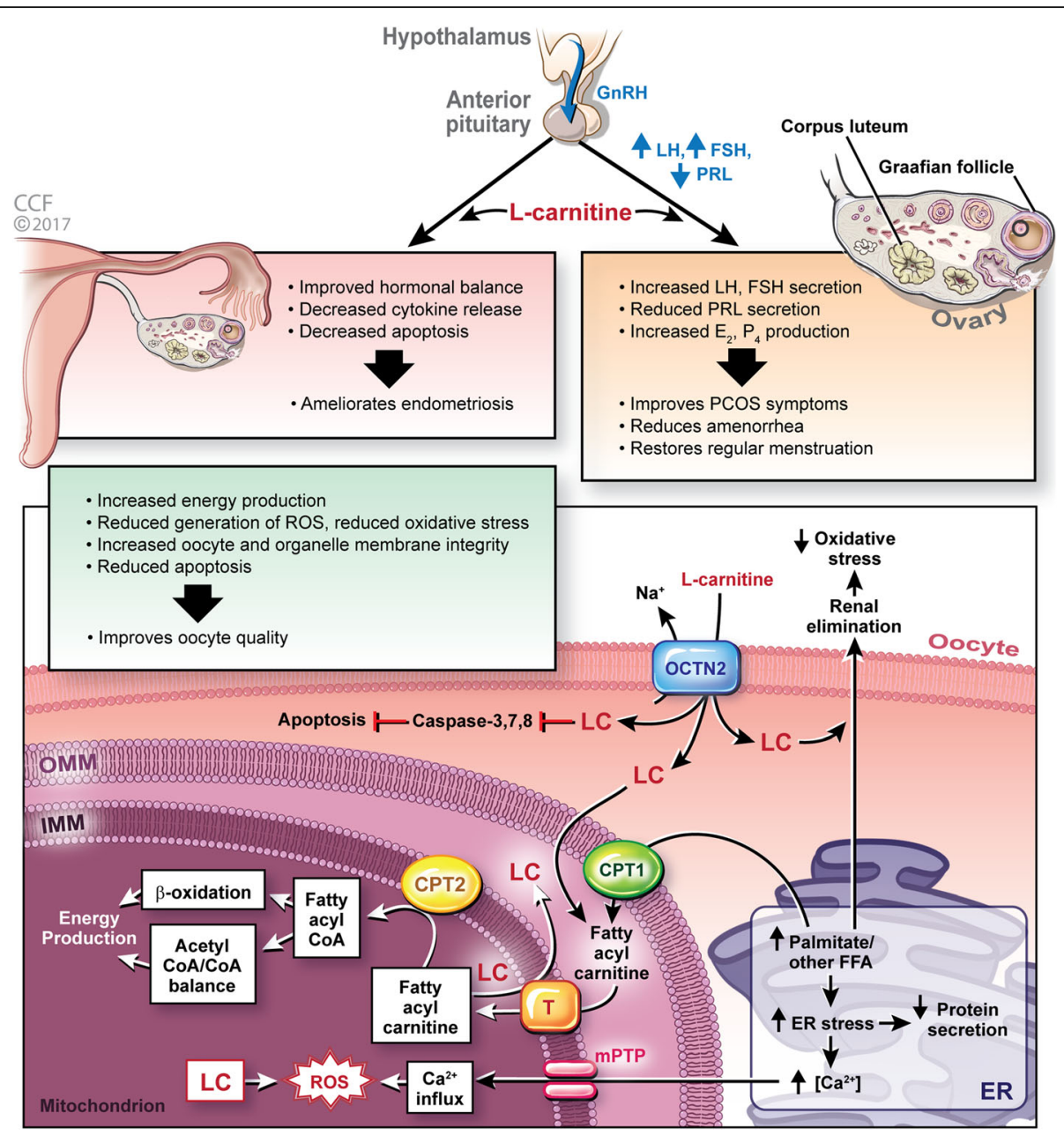

Fig. 2 Mechanism of L-carnitine action on female fertility. LC enters the oocyte through OCTN2 and through its direct action on oocyte quality, it increases energy production by $\beta$-oxidation, eliminates excess palmitate from ER to reduce ER stress, scavenges free radicals to reduce oxidative damage and inhibits caspases to prevent apoptosis. It implies its indirect action through HPG axis by regulating the reproductive hormone levels and thus mitigates reproductive disorders such as PCOS and amenorrhea. In endometriosis, it improves hormonal balance, decreases the release of cytokines as well as apoptosis and thus ameliorates endometriosis. CPT1, carnitine palmitoyltransferase-1; CPT2, carnitine palmitoyltransferase-2; T, CoA, coenzyme-A; ER, endoplasmic reticulum; FFA, free fatty acid; FSH, follicle stimulating hormone; $G n R H$, gonadotropin releasing hormone; IMM, inner mitochondrial membrane; LC, L-carnitine; LH, luteinizing hormone; mPTP, mitochondrial permeability transition pore; OCTN2, organic cation transporter-2; OM, oocyte membrane; OMM, outer mitochondrial membrane; PCOS, polycystic ovary syndrome; PRL, prolactin; ROS, reactive oxygen species; $T$, translocase

cholinomimetic activity [79]. It is reported that LC increases $\mathrm{GnRH}$ secretion from the hypothalamus by acting on the HPG axis $[16,17]$ and causing $\mathrm{K}^{+}$-induced depolarization in hypothalamic neuronal cells to increase its secretory activity $[80,81]$. They have shown that treatment with ALC increases serum levels of other reproductive hormones, like estradiol, progesterone, LH and decreases prolactin in the usual fashion with different phases of estrous in animal $[16,17]$. Through its indirect endocrine effect, it prevents PCOS, amenorrhea and other problems related to the female reproductive cycle.

Costa and Stevenson (1984) with the administration of equine chorionic gonadotropin (eCG) and pregnant mare's serum gonadotropin (PMSG) showed that these components increases ovarian concentration of free LC and ALC, which shows the interaction between the direct and indirect mechanisms through cellular and hormonal regulations [82].

\section{Combination effects with other supplements}

LC or ALC has not only been supplemented individually, in many experiments researchers have supplemented it in combination with other nutrients [20, 21, 44, 83-88] (Table 3). The results of combination treatments i.e. LC and/or ALC with other nutrients are not very well documented in female fertility, but in the last two decades, scientists have started applying LC and/or ALC with other nutrients to improve fertility [84]. It has been 


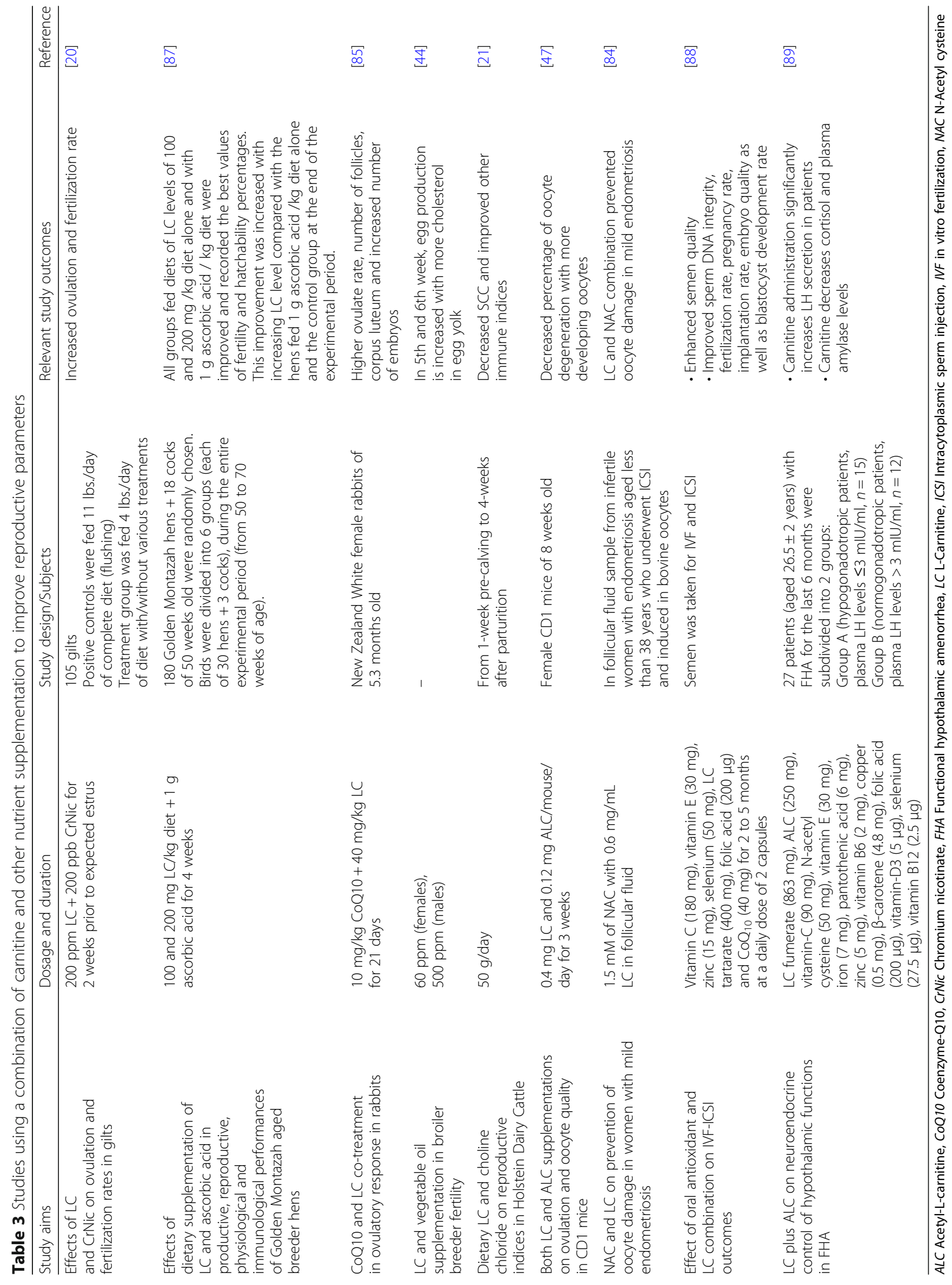


previously reported that $\mathrm{LC}(150 \mathrm{mg} / \mathrm{kg} /$ day $)$ while combined with ginger extract $(100 \mathrm{mg} / \mathrm{kg} /$ day $)$ improves hormonal levels as well as reproductive performance in male rats [83]. It is also known that obestatin and LC co-treatment improves fat metabolism and obesityinduced male infertility [86].

The role of LC in combination with other nutrients on female fertility is also demonstrated by various reports. As discussed earlier, Samland et al. (1998) have recorded the effect of LC supplementation on fertilization rate of gilts; they have not only recorded the effect of individual supplementation of LC (200 ppm), they have also combined it with chromium niconitate ( $\mathrm{CrNic})(200 \mathrm{ppb})$, an insulin promoter which increases insulin uptake by the cells. They have compared the outcomes of both cases in ovulation and fertilization rate and noted that LC individually potentiates ovulation, but when LC was combined with $\mathrm{CrNic}$, it showed no alteration. They concluded that perhaps LC does not interact with $\mathrm{CrNic}$ to cause improvement in reproductive parameters [20].

In 2006, Adabi et al. in contrast, reported the supplementation of LC (60 ppm for females and $500 \mathrm{ppm}$ for males) with vegetable fat powder (1.5\%) and high lysine and methionine $(0.3 \%)$ has increased fertility and hatchability in broilers. They also reported about their interaction as well as their role in lipid metabolism [44]. In 2011, Pirestani et al. supplemented LC individually (50 g/day/cow), as discussed earlier, as well as with choline chloride $(60 \mathrm{~g} / \mathrm{day} / \mathrm{cow})$ on SCC and reproductive indices of Holstein dairy cattle. They have reported choline chloride and LC co-administration has beneficial effects on SCC and reproductive indices, and that is better than individual LC supplementation [21].

In 2011, Hassan et al. supplemented different doses of LC (100 and $200 \mathrm{mg} / \mathrm{kg}$ diet) with vitamin C $(1 \mathrm{~g} / \mathrm{kg}$ diet) for 3 weeks and noted the reproductive performance of Golden Montahza laying hens, and reported increased egg production rate (2.1 and 2.7\%) and egg quality [87]. In 2014, Kacem et al. formulated a special combination of vitamin C (180 mg), vitamin E (30 mg), zinc $(15 \mathrm{mg})$, selenium $(50 \mathrm{mg}), \mathrm{LC}$ tartarate $(400 \mathrm{mg})$, folic acid $(200 \mu \mathrm{g})$ and coenzyme-Q10 $(40 \mathrm{mg})$. They have supplemented this formulation to male participants of a clinical trial of this drug for 2 to 5 months at a daily dose of 2 capsules before their semen has taken for IVF and intra-cytoplasmic sperm injection (ICSI). They have noted that the formulation has not only enhanced semen quality, it also improved sperm DNA integrity, fertilization rate, biochemical and clinical pregnancy rate, implantation rate, embryo quality as well as blastocyst development rate [88].

Cavallini et al. (2012), in their study, reported that 22 out of 33 male patients with severe idiopathic oligoasthenoteratozoospermia (OAT) of infertile couples whose partners had undergone at least one ICSI cycle, showed reduced sperm aneuploidy levels (assessed using fluorescent in situ hybridization performed on chromosomes X, Y, 13, 15, 16, 17, 18, 21 and 22) and improved sperm morphology after 3 months of treatment with LC $2 \times 1$ g/day, ALC $2 \times$ $500 \mathrm{mg} /$ day and cinnoxicam (a lipophilic NSAID) $1 \times$ $30 \mathrm{mg} /$ every 4 days [89]. Men with OAT have been reported to have elevated prostaglandin levels. NSAIDs act by reversibly inhibiting cyclooxygenase, which then inhibits the generation of prostaglandins and thromboxanes. Cinnoxicam and carnitines appear to have complementary mechanistic pathways, which facilitate the suppression of excess prostaglandin production, which could lead to improvement in sperm quality. The men with reduced sperm aneuploidy and improved sperm morphology as a result of the combination therapy in this study had significantly higher biochemical pregnancies, clinical pregnancies and live births after the treatment, despite having similar numbers of oocytes fertilized and embryos transferred [89].

In 2015, Abdel-Khalek et al. reported that coenzyme Q10 $(10 \mathrm{mg} / \mathrm{kg})$ and $\mathrm{LC}(40 \mathrm{mg} / \mathrm{kg})$ for 21 days improved ovulatory response in rabbits, as well as embryo recovery and embryo vitrification in in vitro study [85]. Lastly, Virmani et al. (2015) combined both LC $(0.4 \mathrm{mg} /$ mouse) and ALC (0.12 mg/mouse) with micronutrients like zinc (4 $\mathrm{ng} /$ mouse), copper ( $0.8 \mathrm{ng} /$ mouse) and iron (7 ng/mouse) and treated mice for 3 weeks daily to check the ovulation rate and oocyte quality. They have noted when LC and ALC are given in combination, its actions were better. Similarly, even when carnitines were given in combination with micronutrients, it showed better improvement in oocyte quality and quantity. They have also noted decreased rate of oocyte degeneration as well as increased rate of ovulation while supplemented with microelements. When they have tried this combination for IVF, they observed a better fertilization rate, 2-cell embryo development as well as birth rate [47].

Recently Genazzani et al. (2017) have repeated their experiment of combined LC and ALC effects on female fertility with a formulation containing LC fumerate (863 mg), ALC (250 mg), vitamin C (90 mg), N-acetyl cysteine $(50 \mathrm{mg})$, vitamin $\mathrm{E}(30 \mathrm{mg})$, iron $(7 \mathrm{mg})$, pantothenic acid $(6 \mathrm{mg})$, zinc $(5 \mathrm{mg})$, vitamin B6 $(2 \mathrm{mg})$, copper $(0.5 \mathrm{mg}), \beta$-carotene $(4.8 \mathrm{mg})$, folic acid $(200 \mu \mathrm{g})$, vitamin D3 $(5 \mu \mathrm{g})$, selenium $(27.5 \mu \mathrm{g})$, vitamin B12 $(2.5 \mu \mathrm{g})$. They have reported that this formulation improves the condition of FHA and increases LH. They have also been shown to decrease stress-related cortisol and amylase levels [90].

Most of these reports pointing towards better interactions of LC and/or ALC with other nutrients and antioxidants to enhance fertility rate in female, including 
vitamin C [87, 88], vitamin E [88], zinc [47, 88], selenium [88], folic acid [88], coenzyme- $Q_{10}[47,88]$, vegetable oil containing high lysine [44] and many others [21, 47, 88].

\section{Combination therapies involving other antioxidants in female fertility}

The female reproductive system is vulnerable to oxidative damage and without antioxidant interventions, the copious chain of oxidative reactions would continue to damage the system $[58,91]$. Apart from LC and ALC, as discussed earlier, in conserving and regulating female reproductive functions, there are several groups of antioxidants known to quench free radicals to keep it healthier. These include vitamins ( $C, E$, and $\beta$-carotene), some metallo-enzymes including glutathione peroxidase (GPx, containing selenium), catalase (CAT, containing iron), superoxide dismutase (SOD, containing copper, manganese and zinc). Dietary intake of these antioxidant vitamins and minerals prejudice the coordinated functioning of the total antioxidant system [92].

Within the ovary, various antioxidant systems (consisting of CAT, carotenoids, vitamin E, and glutathione) work to keep ROS under strict regulation. SOD catalyzes the superoxide decomposition into $\mathrm{H}_{2} \mathrm{O}_{2}$ and oxygen, and it has its effects in the theca interna cells of antral follicles. The theca interna cells in turn protect oocyte during its maturation phase from getting damaged by excess ROS. One more antioxidant factor imperative for healthy development of the ovarian follicle is transferrin (iron-chelating glycoprotein) that impedes the generation of ROS [91]. The connection of OS with endometrial cyclical alterations is well accepted and the SOD levels are demonstrated to rise in response to such oxidative changes during the end of the secretory phase, just prior to menstruation [93].

Vitamin C, one of the most commonly used antioxidant, is found in the cytosol of oocyte and extracellular fluid. Its supplementation to infertile women is in practice to treat luteal phase defects and recurrent abortions [58]. It is a versatile vitamin with antioxidant as well as collagen-stimulating properties. Studies revealed that when vitamin $C$ is ingested through diet, the mature ovarian follicles actively take it up leading to its sequestration in the follicles rather than in the serum [58].

During in vitro fertilization (IVF) embryo transfer, vitamin $\mathrm{C}$ supplementation is provided to the patients during hormonal stimulation to ensure higher concentration of vitamin $C$ in the follicular fluid [94]. It effectively breaks the chain of oxidative reactions to stop the promulgation of the peroxidative damage to the oocyte [91]. It is also claimed to elevate the chance of ovulation and protect oocyte from DNA alterations owing to oxidative damage. It helps to regenerate Vitamin $\mathrm{E}$ and glutathione. As discussed earlier, Hassan et al. supplemented vitamin $\mathrm{C}$ with $\mathrm{LC}$ and found improved reproductive performance in hens. This combination has been shown to increase egg production and egg quality thus attributing to reduced OS and improved lipid metabolism following LC-vitamin C co-treatment. Vitamin E ( $\alpha$-tocopherol) is found in the cell membrane of the oocyte and is evidently the first line of defense recruited to disrupt the chain of fatty acid peroxidation protecting the oocyte from further oxidative damage [92]. The follicular and tubular fluid contains taurine, hypotaurine and transferrin which protects the embryo from OS [95]. Glutathione has a role in the improvement of zygote development after the morula or blastocyst gains 2-cell blocks and it is also present in the oocyte as well as in the tubal fluid [96].

Hence, the interplay of antioxidants and their combined effort to combat free radicals, are constantly protecting the delicate organs belonging to the female reproductive system. Antioxidants take charge of their own regeneration as lipoic acid aids in the regeneration of Vitamin C, glutathione, vitamin E as well as of itself, glutathione recycles vitamin $\mathrm{C}$ which in turn recycles vitamin $\mathrm{E}$ that is also regenerated via $\mathrm{CoQ}_{10}$. This battalion of antioxidants, individually or in combination, if associated with LC or ALC, may lead to excellent results in improving female fertility. This can be suggested from the fact that the free radical quenching properties of the above-mentioned antioxidants as well as that of carnitines, when combined with the additional features of the carnitines, such as aiding fatty acid metabolism and energy production, would make the reproductive organs of female more robust.

\section{Conclusions}

This review has summarized the information procured from various research works about the implications of LC and/or ALC upon female fertility. These carnitines, either individually or in combination with other nutrients and antioxidants, are potent to improve and/or restore female reproductive functions. This review has also proposed a mechanism of LC- and ALC-induced enhancement of female fertility, (a) directly by increasing energy production in oocytes and effectively quenching free radicals to provide protection against oxidative damage to the reproductive cells, and also (b) indirectly, by imposing their beneficial effects through HPG axis to ameliorate serum levels of hormones. Thus, considering the substantial qualities of these carnitines in female reproduction, they can be used both as reproductive biomedicines to treat female infertility as well as fertility boosters to improve the reproductive performance in humans and animals.

\section{Abbreviations}

ALC: Acetyl L-Carnitine; ART: Assisted reproductive technology; BCB: Brilliant cresyl blue; CoA: Coenzyme-A; COC: Cumulus-oocyte complex; CPT: Cartinitine palmitoyltransferase; DHEA: Dehydroepiandrosterone; eCG: Equine chorionic 
gonadotropin; ER: Endoplasmic reticulum; FHA: Functional hypothalamic amenorrhea; FISH: Fluorescent in situ hybridization; GABA: $\gamma$-amino butyric acid; GnRH: Gonadotropin releasing hormone; HPG: Hypothalamo-pituitary gonadal axis; IFN: Interferon; IVF: In vitro fertilization; LC: L-carnitine; LDL: Low density lipoprotein; LH: Luteinizing hormone; MII: Metaphase-II; NO: Nitric oxide; OCTN: Organic cation transporter; OS: Oxidative stress; PCOS: Polycystic ovarian syndrome; PG: Prostaglandin; PLC: Propionyl L-carnitine; PMSG: Pregnant mare's serum gonadotropin; ROS: Reactive oxygen species; SCC: Somatic cell count; TNF: Tumor necrosis factor

\section{Acknowledgements}

Authors want to thank American Centre of Reproductive Medicine for providing support for the study.

\section{Funding}

None

\section{Availability of data and materials}

All data supporting the conclusion of this article are included in this published article.

\section{Authors' contributions}

PS (writing and revising the manuscript), DD (writing and revising the manuscript), AA (revising the manuscript). All authors read and approved the final manuscript.

\section{Ethics approval and consent to participate}

Not applicable

\section{Consent for publication}

Not applicable

\section{Competing interests}

The authors declare that they have no competing interests.

\section{Publisher's Note}

Springer Nature remains neutral with regard to jurisdictional claims in published maps and institutional affiliations.

\section{Author details}

${ }^{1}$ American Center for Reproductive Medicine, Cleveland Clinic, Glickman Urological and Kidney Institute, Mail Code X-11, 10681 Carnegie Avenue, Cleveland, OH 44195, USA. ²Department of Physiology, Faculty of Medicine, MAHSA University, Jalan SP2, Bandar Saujana Putra, 42610 Jenjarum, Selangor, Malaysia. ${ }^{3}$ Faculty of Medicine, Universiti Teknologi MARA, Sungai Buloh Campus, Jalan Hospital, 47000 Sungai Buloh, Selangor, Malaysia.

\section{Received: 24 October 2017 Accepted: 17 January 2018}

\section{Published online: 26 January 2018}

\section{References}

1. Rutkowski M, Grzegorczyk K. Adverse effects of antioxidative vitamins. Int Occup Med Environ Health. 2012:25:105-21.

2. May-Panloup P, Chretien MF, Malthiery Y, Reynier P. Mitochondrial DNA in the oocyte and the developing embryo. Curr Top Dev Biol. 2007;77:51-83.

3. Bentov Y, Esfandiari N, Burstein E, Casper RF. The use of mitochondrial nutrients to improve the outcome of infertility treatment in older patients. Fertil Steril. 2010;93:272-5

4. Binienda Z, Virmani A. The Mitochondriotropic effects of L-carnitine and its esters in the central nervous system. Curr Med Chem - Cent Nervous Sys Agents. 2003;3:275-82

5. Dunning KR, Robker RL. Promoting lipid utilization with I-carnitine to improve oocyte quality. Anim Reprod Sci. 2012;134:69-75.

6. Abdelrazik H, Agarwal A. L-carnitine and assisted reproduction. Arch Med Sci. 2009;1A:S43-7

7. Aliabadi E, Soleimani Mehranjani M, Borzoei Z, Talaei-Khozani T, Mirkhani H, Tabesh $\mathrm{H}$. Effects of L-carnitine and L-acetyl-carnitine on testicular sperm motility and chromatin quality. Iran J Reprod Med. 2012;10:77-82.

8. Cheng HJ, Chen T. Clinical efficacy of combined L-carnitine and acetyl-Lcarnitine on idiopathic asthenospermia. Zhonghua Nan Ke Xue. 2008:14: 149-51.
9. Brooks DE. Carnitine, acetylcarnitine and the activity of carnitine acyltransferases in seminal plasma and spermatozoa of men, rams and rats. J Reprod Fertil. 1979; 56:667-73.

10. Dokmeci D. Oxidative stress, male infertility and the role of carnitines. Folia Med (Plovdiv). 2005;47:26-30

11. Ismail AM, Hamed AH, Saso S, Thabet HH. Adding L-carnitine to clomiphene resistant PCOS women improves the quality of ovulation and the pregnancy rate. A randomized clinical trial. Eur J Obstet Gynecol Reprod Biol. 2014;180:148-52.

12. Samimi M, Jamilian M, Ebrahimi FA, Rahimi M, Tajbakhsh B, Asemi Z. Oral carnitine supplementation reduces body weight and insulin resistance in women with polycystic ovary syndrome: a randomized, double-blind, placebo-controlled trial. Clin Endocrinol. 2016;84:851-7.

13. Dunning KR, Russell DL, Robker RL. Lipids and oocyte developmental competence: the role of fatty acids and beta-oxidation. Reproduction. 2014;148:R15-27.

14. Wu GQ, Jia BY, Li JJ, Fu XW, Zhou GB, Hou YP, Zhu SE. L-carnitine enhances oocyte maturation and development of parthenogenetic embryos in pigs. Theriogenology. 2011;76:785-93.

15. Liu J, Head E, Kuratsune H, Cotman CW, Ames BN. Comparison of the effects of $\mathrm{L}$-carnitine and acetyl-L-carnitine on carnitine levels, ambulatory activity, and oxidative stress biomarkers in the brain of old rats. Ann N Y Acad Sci. 2004; 1033:117-31.

16. Krsmanovic LZ, Virmani MA, Stojilkovic SS, Catt KJ. Actions of acetyl-Lcarnitine on the hypothalamo-pituitary-gonadal system in female rats. J Steroid Biochem Mol Biol. 1992;43:351-8.

17. Genazzani AD, Lanzoni C, Ricchieri F, Santagni S, Rattighieri E, Chierchia E, Monteleone P, Jasonni VM. Acetyl-L-carnitine (ALC) administration positively affects reproductive axis in hypogonadotropic women with functional hypothalamic amenorrhea. J Endocrinol Investig. 2011;34:287-91.

18. Latifian S, Hamdi K, Totakneh R. Effect of addition of I-carnitine in polycystic ovary syndrome (PCOS) patients with clomiphene citrate and gonadotropin resistant. Int J Curr Res Acad Rev. 2015;3:469-76.

19. Dionyssopoulou E, Vassiliadis S, Evangeliou A, Koumantakis EE, Athanassakis I. Constitutive or induced elevated levels of L-carnitine correlate with the cytokine and cellular profile of endometriosis. J Reprod Immunol. 2005;65:159-70.

20. Samland CJ, Musser RE, Peters JK, Sawyer JT, Owen KQ, Davis DL Ovulation and fertilization rate of gilts provided additional L-carnitine and chromium nicotinate. In: Kansas Agricultural Experiment Station Research Reports, editor, Swine Day. Manhattan: Agri Exp Station Cooper Ext Service; 1998. p. 25-7.

21. Pirestani A, Aghakhani M, Tabatabaei SN, Ghalamkari G, Baharlo F. Effects of dietary L-carnitine and choline chloride compound on reproduction indices and udder immune system in Holstein dairy cattle. In: Proceedings of international conference on life Science and Technology; 2011. p. 59-61.

22. Reader $\mathrm{KL}$, Cox NR, Stanton JA, Juengel JL. Effects of acetyl-L-carnitine on lamb oocyte blastocyst rate, ultrastructure, and mitochondrial DNA copy number. Theriogenology. 2015:83:1484-92.

23. You J, Lee J, Hyun SH, Lee E. L-carnitine treatment during oocyte maturation improves in vitro development of cloned pig embryos by influencing intracellular glutathione synthesis and embryonic gene expression. Theriogenology. 2012:78:235-43.

24. Gulewitch VS, Krimberg R. Zur Kenntnis der Extraktivstoffe der Muskeln. II. Mitteilung: Über das Carnitin. Zeits für Physiol Chem. 1905:45:326-30.

25. Bremer J. Carnitine-metabolism and Functions. Physiol Rev. 1983;63:1420-80

26. Shug AL, Schmidt MJ, Golden GT, Fariello RG. The distribution and role of carnitine in the mammalian brain. Life Sci. 1982;31:2869-74.

27. Rebouche CJ. Carnitine function and requirements during the life cycle. FASEB J. 1992:6:3379-86

28. Marzo A, Arrigoni Martelli E, Mancinelli A, Cardace G, Corbelletta C, Bassani E, Solbiati M. Protein binding of L-carnitine family components. Eur J Drug Metab Pharmacokinet. 1991;3:364-8.

29. Vassiliadis S, Athanassakis I. A "conditionally essential" nutrient, L-carnitine, as a primary suspect in endometriosis. Fertil Steril. 2011;95:2759-60.

30. Dunning KR, Cashman K, Russell DL, Thompson JG, Norman RJ, Robker RL. Beta-oxidation is essential for mouse oocyte developmental competence and early embryo development. Biol Reprod. 2010;83:909-18.

31. Mingorance C, Rodriguez-Rodriguez R, Justo ML, Herrera MD, de Sotomayor MA. Pharmacological effects and clinical applications of propionyl-L-carnitine. Nutr Rev. 2011;69:279-90

32. Arduini A, Denisova N, Virmani A, Avrova N, Federici G, Arrigoni-Martelli E. Evidence for the involvement of carnitine-dependent long-chain acyltransferases 
in neuronal triglyceride and phospholipid fatty acid turnover. J Neurochem. 1994; 62:1530-8.

33. Abdelrazik H, Sharma R, Mahfouz R, Agarwal A. L-carnitine decreases DNA damage and improves the in vitro blastocyst development rate in mouse embryos. Fertil Steril. 2009;91:589-96.

34. Infante JP, Tschanz CL, Shaw N, Michaud AL, Lawrence P, Brenna JT. Straight-chain acyl-CoA oxidase knockout mouse accumulates extremely long chain fatty acids from alpha-linolenic acid: evidence for runaway carousel-type enzyme kinetics in peroxisomal beta-oxidation diseases. Mol Genet Metab. 2002;75:108-19.

35. Varnagy A, Bene J, Sulyok E, Kovacs GL, Bodis J, Melegh B. Acylcarnitine esters profiling of serum and follicular fluid in patients undergoing in vitro fertilization. Reprod Biol Endocrinol. 2013;11:67.

36. Fenkci SM, Fenkci V, Oztekin O, Rota S, Karagenc N. Serum total L-carnitine levels in non-obese women with polycystic ovary syndrome. Hum Reprod. 2008;23:1602-6.

37. Christiana K, George T, George F, Margarita T, Anna T, Costas F, Irene A. Lcarnitine alters lipid body content in pre-implantation embryos leading to infertility. J Reprod Immunol. 2014;101-102:18-39.

38. Mansour G, Abdelrazik H, Sharma RK, Radwan E, Falcone T, Agarwal A. Lcarnitine supplementation reduces oocyte cytoskeleton damage and embryo apoptosis induced by incubation in peritoneal fluid from patients with endometriosis. Fertil Steril. 2009;91:2079-86.

39. Center SA, Warner KL, Randolph JF, Sunvold GD, Vickers JR. Influence of dietary supplementation with (L)-carnitine on metabolic rate, fatty acid oxidation, body condition, and weight loss in overweight cats. Am J Vet Res. 2012;73:1002-15.

40. Jamilian H, Jamilian M, Samimi M, Afshar Ebrahimi F, Rahimi M, Bahmani F, Aghababayan S, Kouhi M, Shahabbaspour S, Asemi Z. Oral carnitine supplementation influences mental health parameters and biomarkers of oxidative stress in women with polycystic ovary syndrome: a randomized, double-blind, placebo-controlled trial. Gynecol Endocrinol. 2017;33:442-7.

41. Meczekalski B, Katulski K, Czyzyk A, Podfigurna-Stopa A, Maciejewska-Jeske M. Functional hypothalamic amenorrhea and its influence on women's health. J Endocrinol Investig. 2014;37:1049-56.

42. MBMR F, Flayyih NK. Effect of L-carnitine administration to pregnant mice on some reproductive hormones and organs. Iraqi I Vet Med. 2012;36:68-74.

43. Zhai W, Neuman SL, Latour MA, Hester PY. The effect of male and female supplementation of $\mathrm{L}$-carnitine on reproductive traits of white leghorns. Poult Sci. 2008;87:1171-81.

44. Adabi SG, Moghaddam G, Taghizadeh A, Nematollahi A, Farahvash T. Effect of L-carnitine and vegetable fat on broiler breeder fertility, hatchability, egg yolk and serum cholesterol and triglyceride. Int J Poult Sci. 2006;5:970-4.

45. Tselekidou A, Athanassakis I. PGE1 versus PGE2: protective rather than inducing agent for endometriosis. Eur J Immunol. 2009;81:165.

46. Dionyssopoulou E, Anagnostaki E, Tselekidou A, Vassiliadis S, Athanassakis I. Establishment or aggravation of endometriosis-induction process. In: Arici A Matalliotakis I, editors. Endometriosis-adenomyosis. Greece: PM Publications; 2011.

47. Virmani MA, Zerelli S, Vitullo P, Cossetti C. Effect Of nutrients on ovulation and oocytes quality in mice. In: Proceedings of 11 th congress of the European Society of Gynecology. Roma: Edizioni Internazionali; 2015. p. 212-4.

48. Virmani MA, Virtullo P, Cossetti C. Improving Oocyte and Sperm Quality by L-Carnitine, Acetyl-L-carnitine and Other Nutrients as Major Determinant in Pregnancy Success. Journal of Perinatal Medicine. 45 Supplement. 2017;1:3.

49. Canbolat EP, Sagsoz N, Noyan V, Yucel A, Kisa U. Effects of I-carnitine on oxidative stress parameters in oophorectomized rats. Alex J Med. 2017;53: 55-60.

50. Corduk M, Sarica S. Effects of L-carnitine in layer diets containing different fat sources and energy levels on hen performance and egg quality. South Afr J Anim Sci. 2008:38:260-70.

51. Ramanau A, Kluge H, Spilke J, Eder K. Reproductive performance of sows supplemented with dietary L-carnitine over three reproductive cycles. Arch Tierernahr. 2002;56:287-96.

52. Musser RE, Dritz SS, Davis DL, Tokach MD, Nelssen JL, Goodband RD, Owen KQ. Effects of $\mathrm{L}$-carnitine in the gestating sow diet on fetal muscle development and carcass characteristics of the offspring. J Appl Anim Res. 2007;31:105-11.

53. Scholz H, Heimendahl EV, Menn F, Ahrens A. Application of Protected LCarnitine in Dairy Cows during Transition and High Lactation Period. Global J Sci Front Res. 2014;XIV:41-6.

54. Somfai T, Kaneda M, Akagi S, Watanabe S, Haraguchi S, Mizutani E, DangNguyen TQ, Geshi M, Kikuchi K, Nagai T. Enhancement of lipid metabolism with L-carnitine during in vitro maturation improves nuclear maturation and cleavage ability of follicular porcine oocytes. Reprod Fertil Dev. 2011;23:912-20.

55. Moawad AR, Xu B, Tan SL, Taketo T. L-carnitine supplementation during vitrification of mouse germinal vesicle stage-oocytes and their subsequent in vitro maturation improves meiotic spindle configuration and mitochondrial distribution in metaphase II oocytes. Hum Reprod. 2014;29:2256-68.

56. Mishra A, Reddy IJ, Gupta PS, Mondal S. L-carnitine mediated reduction in oxidative stress and alteration in transcript level of antioxidant enzymes in sheep embryos produced in vitro. Reprod Domest Anim. 2016;51:311-21.

57. Pillich RT, Scarsella G, Risuleo G. Reduction of apoptosis through the mitochondrial pathway by the administration of acetyl-L-carnitine to mouse fibroblasts in culture. Exp Cell Res. 2005;306:1-8.

58. Agarwal A, Gupta S, Sharma RK. Role of oxidative stress in female reproduction. Reprod Biol Endocrinol. 2005;3:28.

59. Carlberg M, Nejaty J, Froysa B, Guan Y, Soder O, Bergqvist A. Elevated expression of tumour necrosis factor alpha in cultured granulosa cells from women with endometriosis. Hum Reprod. 2000;15:1250-5.

60. Bedaiwy MA, Falcone T. Peritoneal fluid environment in endometriosis. Clinicopathological implications. Minerva Ginecol. 2003;55:333-45.

61. Gupta S, Goldberg JM, Aziz N, Goldberg E, Krajcir N, Agarwal A. Pathogenic mechanisms in endometriosis-associated infertility. Fertil Steril. 2008;90:247-57.

62. Glabowski W, Kurzawa R, Wiszniewska B, Baczkowski T, Marchlewicz M, Brelik P. Growth factors effects on preimplantation development of mouse embryos exposed to tumor necrosis factor alpha. Reprod Biol. 2005;5:83-99.

63. Whiteside EJ, Boucaut KJ, Teh A, Garcia-Aragon J, Harvey MB, Herington AC. Elevated concentration of TNF-alpha induces trophoblast differentiation in mouse blastocyst outgrowths. Cell Tissue Res. 2003;314:275-80.

64. Zare Z, Masteri Farahani R, Salehi M, Piryaei A, Ghaffari Novin M, Fadaei Fathabadi F, Mohammadi M, Dehghani-Mohammadabadi M. Effect of L-carnitine supplementation on maturation and early embryo development of immature mouse oocytes selected by brilliant cresyle blue staining. J Assist Reprod Genet. 2015;32:635-43.

65. Bareh GM. The effect of endometriosis on the DNA integrity of different stages of Embryos' development and the role of L-carnitine in preventing damage to early stages. J Minimal Inv Gynecol. 2010;17:S51.

66. Phongmitr T, Liang Y, Srirattana K, Panyawai K, Sripunya N, Treetampinich C, Parnpai R. Effects of $\mathrm{L}$-carnitine supplemented in maturation medium on the maturation rate of swamp buffalo oocytes. Buffalo Bulletin. 2013;32:613-6.

67. Ghanem N. L-carnitine improved bovine blastocyst rate and quality when supplemented at different preimplantation stages. Egypt J Anim Prod. 2015; 52:89-99.

68. Takahashi T, Inaba Y, Somfai T, Kaneda M, Geshi M, Nagai T, Manabe N. Supplementation of culture medium with $\mathrm{L}$-carnitine improves development and cryotolerance of bovine embryos produced in vitro. Reprod Fertil Dev. 2013;25:589-99.

69. Ghanem N, Ha AN, Fakruzzaman M, Bang Jl, Lee SC, Kong IK. Differential expression of selected candidate genes in bovine embryos produced in vitro and cultured with chemicals modulating lipid metabolism. Theriogenology. 2014:82:238-50

70. Manzano PCVJ, Ocampo MB, Ocampo LC, Maylem ERS, Lazaro JV. Improved bovine blastocyst developmental potential by L-carnitine supplementation. Int J Sci Res Knowledge. 2015;3:021-9.

71. Khanmohammadi N, Movahedin M, Safari M, Sameni HR, Yousefi B, Jafari B, Zarbakhsh S. Effect of L-carnitine on in vitro developmental rate, the zona pellucida and hatching of blastocysts and their cell numbers in mouse embryos. Int J Reprod Biomed (Yazd). 2016;14:649-56.

72. Vanella A, Russo A, Acquaviva R, Campisi A, Di Giacomo C, Sorrenti V, Barcellona ML. L -Propionyl-carnitine as superoxide scavenger, antioxidant, and DNA cleavage protector. Cell Biol Toxicol. 2000;16:99-104.

73. Stojkovic M, Machado SA, Stojkovic P, Zakhartchenko V, Hutzler P, Goncalves $\mathrm{PB}$, Wolf E. Mitochondrial distribution and adenosine triphosphate content of bovine oocytes before and after in vitro maturation: correlation with morphological criteria and developmental capacity after in vitro fertilization and culture. Biol Reprod. 2001;64:904-9.

74. Tamai I, Ohashi R, Nezu J, Yabuuchi H, Oku A, Shimane M, Sai Y, Tsuji A. Molecular and functional identification of sodium ion-dependent, high affinity human carnitine transporter OCTN2. J Biol Chem. 1998;273: 20378-82.

75. Bedaiwy MA, Falcone T, Mohamed MS, Aleem AA, Sharma RK, Worley SE, Thornton J, Agarwal A. Differential growth of human embryos in vitro: role of reactive oxygen species. Fertil Steril. 2004;82:593-600. 
76. Virmani MA, Krsmanovic LZ, Stojilkovic SS, Catt KJ. Stimulatory effects of Lacetyl carnitine on the pituitary-gonadal axis in female rats. In: Advances in human female reproduction. New York: Sereno Symposium Publication, Raven Press; 1991. p. 291-6.

77. Bresolin N, Freddo L, Vergani L, Angelini C. Carnitine, carnitine acyltransferases, and rat brain function. Exp Neurol. 1982;78:285-92.

78. Amenta F, Cavallotti C, De Rossi M, Bossoni G, Carpi C. Effect of acetylL-carnitine treatment on some behavioural, histochemical and histological parameters of methylazoxymethanol microencephalic rats. Int J Tissue React. 1986;8:513-26.

79. Bodis-Wollner I. Physiological effects of acetyl-levo-carnitine in the central nervous system. Int J Clin Pharmacol Res. 1990;10:109-14.

80. Bigdeli H, Snyder PJ. Gonadotropin releasing hormone release from the rat hypothalamus: dependence on membrane depolarization and calcium influx. Endocrinology. 1978;103:281-6.

81. Krsmanovic LZ, Virmani MA, Stojilkovic SS, Catt KJ. Stimulation of gonadotropinreleasing hormone secretion by acetyl-L-carnitine in hypothalamic neurons and GT1 neuronal cells. Neurosci Lett. 1994;165:33-6.

82. Costa ND, Stevenson PM. Changes in coenzyme a and carnitine concentrations in superovulated rats. Biochim Biophys Acta. 1984;792:130-4.

83. Abo-Ghanema II, El-Nasharty MA, El-Far AH, Ghonium HA. Effect of ginger and $\mathrm{L}$-carnitine on the reproductive performance of male rats. World Acad Sci Eng Technol. 2012;64:980-6.

84. Giorgi VS, Da Broi MG, Paz CC, Ferriani RA, Navarro PA. N-acetyl-cysteine and I-carnitine prevent meiotic oocyte damage induced by follicular fluid from infertile women with mild endometriosis. Reprod Sci. 2016:23:342-51.

85. Abdel-Khalek AE, El-Ratel IT, Wafa WM, El-Nagar HA, Younan GE, Fouda SF. Effect of pre-conception coenzyme Q10 and L-carnitine treatments on ovulatory response, genital characteristics and in vitro embryo characteristics in rabbits. Asian J Anim Vet Adv. 2015;11:53-9.

86. El-Damarawi MA, Salama ME. Obestatin and L-carnitine as a defensive strategy against fertility disorders induced by obesity in male rats. Tanta Med J. 2014;42: 103-11.

87. MSH H, Youssef SF, El-bahy MA. Effects of L-carnitine and ascorbic acid supplementation on productive, reproductive, physiological and immunological performance of golden montazah laying hens. Egypt Poult Sci. 2011;31:557-78.

88. Kacem O, Harzallah M, Zedini C, Zidi I, Meddeb S, Fekih M, Saidi H, Chaib A, Boughizane S, Ali HB, et al. Beneficial effect of an oral antioxidant supplementation (Fertimax2) on IVF-ICSI outcomes: a preliminary clinical study. Adv Reprod Sci. 2014;2:47-56.

89. Cavallini G, Magli MC, Crippa A, Ferraretti AP, Gianaroli L. Reduction in sperm aneuploidy levels in severe oligoasthenoteratospermic patients after medical therapy: a preliminary report. Asian J Androl. 2012;14:591-8.

90. Genazzani AD, Despini G, Czyzyk A, Podfigurna A, Simoncini T, Meczekalski B. Modulatory effects of I-carnitine plus I-acetyl-carnitine on neuroendocrine control of hypothalamic functions in functional hypothalamic amenorrhea (FHA). Gynecol Endocrinol. 2017:1-5.

91. Sekhon LH, Gupta S, Kim Y, Agarwal A. Female infertility and antioxidants. Curr Women's Health Rev. 2010;6:84-95.

92. McDowell LR, Wilkinson N, Madison R, Felix T. Vitamins and minerals functioning as antioxidants with supplementation considerations. In: Florida Ruminant Nutrition Symposium. Gainesville, FL: Best Western Gateway Grand; 2007. p. 30-1.

93. Sugino N, Karube-Harada A, Taketani T, Sakata A, Nakamura Y. Withdrawal of ovarian steroids stimulates prostaglandin F2alpha production through nuclear factor-kappaB activation via oxygen radicals in human endometrial stromal cells: potential relevance to menstruation. J Reprod Dev. 2004;50: 215-25.

94. Crha I, Hruba D, Ventruba P, Fiala J, Totusek J, Visnova H. Ascorbic Acid and infertility treatment. Cent Eur J Public Health. 2003;11:63-7.

95. Guerin P, El Mouatassim S, Menezo Y. Oxidative stress and protection against reactive oxygen species in the pre-implantation embryo and its surroundings. Hum Reprod Update. 2001;7:175-89.

96. de Matos DG, Furnus CC. The importance of having high glutathione (GSH) level after bovine in vitro maturation on embryo development effect of beta-mercaptoethanol, cysteine and cystine. Theriogenology. 2000;53:761-71.

\section{Submit your next manuscript to BioMed Central and we will help you at every step:}

- We accept pre-submission inquiries

- Our selector tool helps you to find the most relevant journal

- We provide round the clock customer support

- Convenient online submission

- Thorough peer review

- Inclusion in PubMed and all major indexing services

- Maximum visibility for your research

Submit your manuscript at www.biomedcentral.com/submit
Biomed Central 